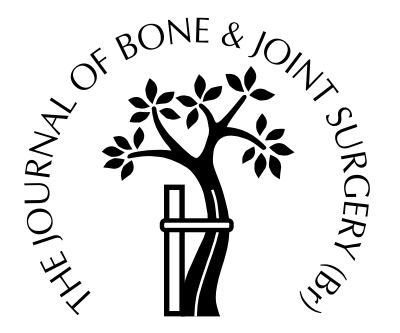

\title{
A prospective randomised trial of internal fixation versus arthroplasty for displaced fractures of the neck of the femur
} FUNCTIONAL OUTCOME FOR 450 PATIENTS AT TWO YEARS

\author{
C. Rogmark, Å. Carlsson, O. Johnell, I. Sernbo
}

From Malmö University Hospital, Sweden

$I^{t}$ remains a matter of debate whether displaced fractures of the neck of the femur should be treated by internal fixation or arthroplasty. We have compared the two methods with regard to complications, mortality and functional outcome.

We studied 409 patients, aged 70 years and over, with subcapital fractures graded as Garden 3 or 4, in a two-year prospective multicentre study from 12 Swedish hospitals. They were randomised to internal fixation or arthroplasty. Patients who were mentally confused, bedridden or in a nursing-home were excluded from the survey.

After two years the rate of failure was $43 \%$ in the internal fixation (IF) and $6 \%$ in the arthroplasty group (p<0.001). In the IF group $36 \%$ had impaired walking and $6 \%$ had severe pain compared with $25 \%$ and $1.5 \%$, respectively, in the arthroplasty group (both $\mathbf{p}<0.05$ ). There was no difference in mortality.

With a high rate of failure and poor functional outcome after IF, we recommend primary arthroplasty for displaced fractures of the neck of the femur in patients over 70 years of age.

J Bone Joint Surg [Br] 2002;84-B:183-8.

Received 23 November 2000; Accepted after revision 22 May 2001

Primary arthroplasty or closed reduction and internal fixation (IF) with nails or screws are the two main options for the treatment of displaced fractures of the neck of the femur. Approximately 9000 such fractures occur annually in Sweden, and two-thirds of these are displaced. ${ }^{1}$ IF has been the method of choice in Scandinavia, while other countries prefer primary arthroplasty. The question as to whether the femoral head should be replaced or retained has been addressed by several authors, but there have been

\footnotetext{
C. Rogmark, MD, PhD, Student

A. Carlsson, MD, PhD, Associate Professor

O. Johnell, MD, PhD, Professor

I. Sernbo, MD, PhD, Associate Professor

Department of Orthopaedics, Malmö University Hospital, SE-205 02 Malmö, Sweden.

Correspondence should be sent to Dr C. Rogmark.
}

(C)2002 British Editorial Society of Bone and Joint Surgery 0301-620X/02/211923\$2.00 only a few prospective, correctly randomised ${ }^{2-5}$ or randomly allocated studies ${ }^{6}$ which have compared the two methods. Lu-Yao et $\mathrm{al}^{7}$ carried out a meta-analysis of 106 reports and found limitations in the available data. They pointed out the necessity for rigorous studies in this field.

We have compared the two methods with regard to complications, mortality and functional outcome in a large series of patients.

\section{Patients and Methods}

Between 1995 and 1997, 450 patients, aged 70 years and over, with fractures of the hip graded as Garden 3 or 4 were included in a two-year prospective, randomised, multicentre study from 12 hospitals in Sweden (Halmstad, Helsingborg, Hässleholm, Karlshamn, Karlskrona, Kristianstad, Landskrona, Ljungby, Lund, Malmö, Ystad and Ängelholm). Patients with confusion or rheumatoid arthritis were excluded, as well as those who were bedridden or confined to a nursing-home. Those with fractures older than two days were also excluded. The patients were randomised to either IF or arthroplasty by means of sealed, numbered, opaque envelopes. The study was approved by the Ethics Committee and the patients gave informed consent.

Forty-one patients $(9 \%)$ were excluded for the following reasons: the planned surgery, usually arthroplasty, was cancelled for anaesthetic reasons (10), the patients were lost to follow-up (8), they did not meet the inclusion criteria (7) or they refused to continue in the study (13). Three patients died before operation.

In addition, 26 patients were too weak to attend the twoyear review. These were included with their recorded state at one year.

There were therefore 324 women $(79 \%)$ with a mean age of 81.8 years (SD 5.8) and 85 men $(21 \%)$ with a mean age of 80.7 years (SD 5.9) included in the study. The mean age in the two groups was the same, 81.5 years. There were 170 women $(78 \%)$ in the IF group and $154(80 \%)$ in the arthroplasty group.

Using a score reflecting the patients' age, home circumstances, walking ability and mental status, the choice between total hip arthroplasty (THA) or hemiarthroplasty was made (Table I). The arthroplasty group consisted of 192 patients, 103 of whom had THA and 89 hemi- 
Table I. The Sernbo score. A sum of 15 or more indicates that the patient should have a THA, less than 15 a hemiarthroplasty

\begin{tabular}{ll}
\hline & Points \\
\hline Age (yrs) & \\
70 to 80 & 5 \\
$>80$ & 2 \\
Habitat & \\
$\quad$ Own home & 5 \\
$\quad$ Sheltered home & 2 \\
Walking aids & \\
$\quad$ One cane or none & 5 \\
$\quad$ Canes, walking frame & 2 \\
Mental status & \\
$\quad$ Alert & 5 \\
$\quad$ Slight confusion & 2 \\
\hline
\end{tabular}

Table II. The implants used in the study

\begin{tabular}{lrr}
\hline & Number & Percentage \\
\hline Internal fixation $(\mathrm{n}=217)$ & & \\
$\quad$ Hansson hook-pins & 200 & 92 \\
$\quad$ Olmed screws & 17 & 8 \\
Total arthroplasty $(\mathrm{n}=103)$ & & \\
$\quad$ Exeter & 33 & 32 \\
Charnley & 32 & 31 \\
Lubinus & 19 & 18 \\
Scanhip & 14 & 14 \\
Others & 5 & 5 \\
Hemiarthroplasty $(\mathrm{n}=89)$ & & \\
$\quad$ Variokopf & 41 & 46 \\
$\quad$ Moore & 17 & 19 \\
Charnley-Hastings & 14 & 16 \\
Others & 17 & 19 \\
\hline
\end{tabular}

arthroplasty. Contributing hospitals used the type of prosthesis and surgical approach with which they were familiar (Table II). All the surgeons involved were experienced with the techniques of fixation and arthroplasty. The postoperative care in both groups was the same. Early weightbearing was encouraged and regular physiotherapy was provided.

The primary endpoint was failure, defined in the IF group as early redisplacement of the fracture, nonunion, segmental collapse of the femoral head or deep infection. Neither local irritation from the pin ends nor extraction of the pins when the fracture had healed were classified as failures. In the arthroplasty group, two or more dislocations, loosening, deep infection or femoral fracture adjacent to the prosthesis were defined as failures.

All patients were followed up by clinical and radiological examinations at 4, 12 and 24 months after surgery. A standardised questionnaire was used which included preoperative social and medical factors and walking ability. There were no significant differences between the treatment groups.

According to 'intention-to-treat' rules, each patient kept the 'label' from the randomisation, i.e., an IF patient was still an IF patient even after reoperation by arthroplasty. Patients who died during the follow-up, but attended at least one postoperative examination, were included in the results concerning failure, with their latest known status.

Statistical analysis. The power analysis showed a power of $90 \%$ to detect a difference of $15 \%$. Statistical analysis was made by the chi-squared test, the Mann-Whitney U test and survival analysis with life tables and the log-rank test (Statistica for Windows, 1999 edition, StatSoft Inc, USA).

\section{Results}

The perioperative mortality was $1.2 \%$, the mortality at one year $13 \%$ and at two years $21 \%$, with no significant difference between the groups at any point (Table III). Men had a significantly higher mortality than women at 4,12 and 24 months.

The waiting time between admission and surgery, the duration of surgery and the length of hospital stay are shown in Table IV. All three parameters were significantly shorter in the IF group. In the IF group 101 of 217 patients $(47 \%)$ were discharged directly to their homes, compared with 75 of $192(39 \%)$ in the arthroplasty group. There was no significant difference between the groups. When all complications during the hospital stay were summarised, the arthroplasty group had a significantly higher frequency of complications; 45 of 192 patients (23\%) had a complication compared with 33 of $217(15 \%)$ in the IF group $(\mathrm{p}=0.047)$. When comparing the incidence of each complication, there was no significant difference between the groups. Three patients in each group had pressure sores, nine in the arthroplasty and eight in the IF group had pulmonary and/or cardiac insufficiency, and five and three,

Table III. Cumulative mortality of the patients during follow-up

\begin{tabular}{|c|c|c|c|c|c|c|c|c|c|c|c|c|}
\hline & \multicolumn{3}{|c|}{ During hospital stay } & \multicolumn{3}{|c|}{ Up to 4 months } & \multicolumn{3}{|c|}{ Up to 12 months } & \multicolumn{3}{|c|}{ Up to 24 months } \\
\hline & Number & $\%$ & p value & Number & $\%$ & p value & Number & $\%$ & p value & Number & $\%$ & p value \\
\hline All patients $(n=409)$ & 5 & 1.2 & & 25 & 6.1 & & 55 & 13 & & 87 & 21 & \\
\hline IF $(n=217)$ & 2 & 0.9 & NS & 11 & 5.0 & NS & 27 & 12 & NS & 46 & 21 & NS \\
\hline Arthroplasty $(\mathrm{n}=192)$ & 3 & 1.6 & & 14 & 7.3 & & 28 & 15 & & 41 & 21 & \\
\hline All men $(\mathrm{n}=85)$ & 1 & 1.2 & NS & 11 & 13 & 0.009 & 18 & 21 & 0.036 & 28 & 33 & 0.008 \\
\hline All women $(n=324)$ & 4 & 1.2 & & 14 & 4.3 & & 37 & 11 & & 59 & 18 & \\
\hline
\end{tabular}


Table IV. Details of the operations for the patients in the study (median values and ranges)

\begin{tabular}{llll}
\hline & Waiting time (hrs) & Duration of surgery (mins) & Length of hospital stay (days)* \\
\hline IF & $18(1$ to 104$)$ & $27(5$ to 220$)$ & $10(2$ to 37$)$ \\
Arthroplasty & $24(1$ to 192$)$ & $80(20$ to 290$)$ & $12(5$ to 44$)$ \\
p value & $<0.001$ & $<0.001$ & $<0.001$ \\
\hline
\end{tabular}

* patients who died during hospital stay were excluded

Table V. Reasons for failure in each group

\begin{tabular}{lcc}
\hline & Number & Percentage \\
\hline Internal fixation $(\mathrm{n}=217)$ & & \\
$\quad$ Nonunion* & 60 & 28.0 \\
Avascular necrosis & 26 & 12.0 \\
Deep infection & 1 & 0.5 \\
Pain & 6 & 2.8 \\
Total & 93 & 43.0 \\
Arthroplasty $(\mathrm{n}=192)$ & & \\
Dislocations $(>1) \dagger$ & 8 & 4.2 \\
Diaphyseal femoral fracture & 3 & 1.6 \\
Deep infection & 1 & 0.5 \\
Total & 12 & 6.3 \\
\hline * including early redisplacement of fracture \\
+ more than once
\end{tabular}

Table VI. Life table of deceased patients and failed cases in each group

\begin{tabular}{lcllll}
\hline & $\begin{array}{l}\text { Interval } \\
\text { start } \\
\text { (mths) }\end{array}$ & $\begin{array}{l}\text { Number } \\
\text { entering }\end{array}$ & $\begin{array}{l}\text { Deceased or } \\
\text { not present }\end{array}$ & Failure & $\begin{array}{l}\text { Cumulative } \\
\text { success } \\
\text { rate }(\%)\end{array}$ \\
\hline IF (n=217) & 0 & 217 & 11 & 44 & 100 \\
& 4 & 162 & 11 & 35 & 79 \\
& 12 & 116 & 18 & 14 & 61 \\
Arthroplasty (n=192) & 24 & 84 & & & 53 \\
& 4 & 192 & 14 & 8 & 100 \\
& 12 & 170 & 18 & 4 & 95 \\
& 24 & 148 & 23 & 0 & 93 \\
\hline
\end{tabular}

Table VII. Number of patients reoperated on in each group

\begin{tabular}{lc}
\hline & Number \\
\hline IF & 53 \\
Total hip arthroplasty & 31 \\
Hemiarthroplasty & 15 \\
Extraction of pins & 2 \\
Girdlestone procedure only & 2 \\
Girdlestone procedure followed by THA & 3 \\
Revision surgery (exchange of component) & \\
Arthroplasty & 15 \\
Closed reduction with anaesthesia* & 1 \\
Revision surgery (exchange of component) & 2 \\
Conversion of hemi- to total arthroplasty $\dagger$ & 2 \\
Femoral fracture surgery & \\
\hline some patients had more than one reduction & \\
$\dagger$ one case with concurrent femoral fracture &
\end{tabular}

respectively, had had a stroke. During the follow-up period two patients in the arthroplasty and five in the IF group had a venous thromboembolic complication.

The results at two-years show that the total failure rate for patients in the IF group was 43\% (93/217 patients), compared with $6 \%(12 / 192$ patients) in the arthroplasty group $(\mathrm{p}<0.001)$. There was one deep infection in each group. The fracture-related complications are given in Table V.

Survival analysis shows a cumulative success rate of $53 \%$ in the IF group at 24 months compared with $92 \%$ in the arthroplasty group (log rank test, $\mathrm{p}>0.001$; Table VI).

Of the patients with failed IF, $96 \%$ were reoperated on or reoperation was planned by two years. Only four of 92 patients were considered to be unfit for surgery. At four months $25 \%$ of the IF group had revision operations. Any reoperations performed are shown in Table VII.

Eight arthroplasty patients suffered from recurrent dislocations; three had diaphyseal femoral fractures. Two with dislocations and one with a fracture had revision surgery. The other patients with dislocations had hips which were stable at two years, with one exception, and did not need further surgery.

Seven patients had only one dislocation, giving a total rate of $8 \%(15 / 192)$. At two years three patients showed radiological signs of loosening and one had heterotopic bone formation. One of these died shortly afterwards. The three survivors had slight hip pain and two had restricted mobility because of their hip. An 'uncertain' status at two years was noted in nine patients in the IF group because of suspected avascular necrosis. There were no significant differences between THA and hemiarthroplasty with regard to complications, although all three femoral fractures occurred in the hemiarthroplasty group. Two of these had uncemented Moore prostheses.

Women in the IF group had a significantly higher rate of failure than men: $46 \%$ (78/170) compared with $30 \%$ $(14 / 47)(p=0.048)$. By contrast, women with an arthroplasty had a lower failure rate than men: $6 \%$ compared with $8 \%$, but the difference was not significant.

The IF group reported significantly more problems from their hip when walking throughout the follow-up period. In the questionnaire, the patients were asked if they considered their walking ability to be the same as before the fracture. If not, they were asked if it was because of the hip or for other reasons.

In the IF group $36 \%$ had reduced mobility because of symptoms from the hip compared with $25 \%$ in the arthroplasty group at two years $(\mathrm{p}<0.05$; Fig. 1$)$. The ability to 


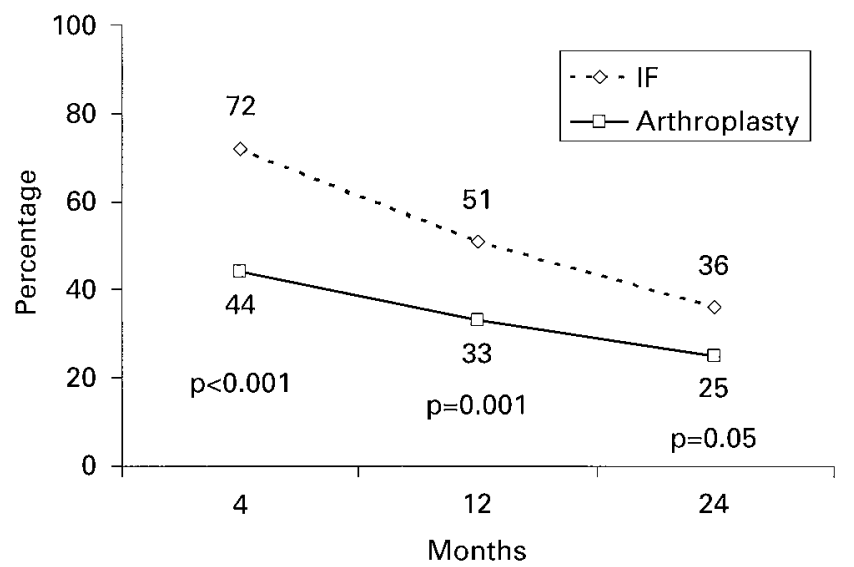

Fig. 1

Graph showing percentage of patients who reported reduced mobility because of symptoms from the hip (\%).

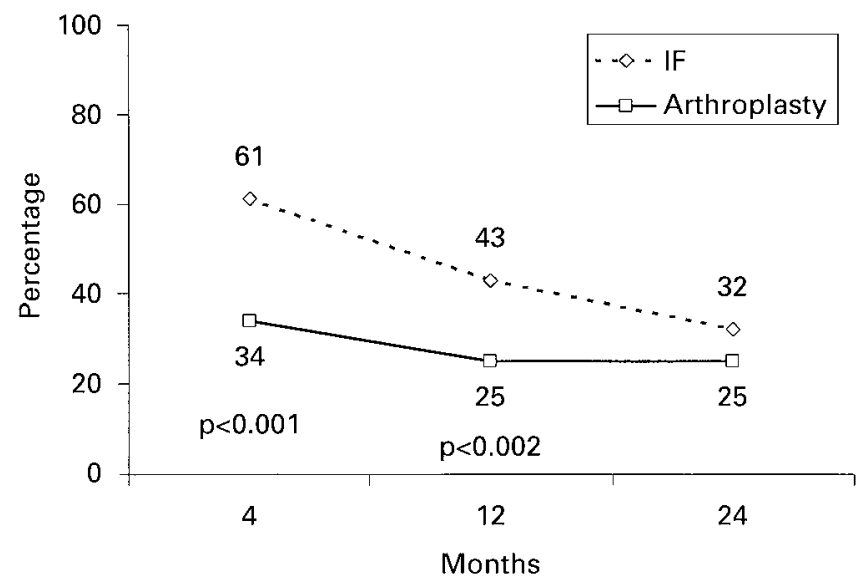

Fig. 3

Graph showing percentage of patients reporting hip pain on walking.

walk up stairs followed the same pattern, with significantly less function in the IF group at 4 and 24 months (Fig. 2).

Severe or slight hip pain when walking was reported by $61 \%$ in the IF group at four months, compared with $34 \%$ in the arthroplasty group $(\mathrm{p}<0.001)$. At 12 months the corresponding figures were $43 \%$ and $25 \%$ ( $p<0.002$; Fig. 3). Severe pain occurred in $6 \%$ in the IF group compared with $1.5 \%$ in the arthroplasty group at two years $(\mathrm{p}<0.05)$.

At four months the arthroplasty group had significantly less need of walking aids than the IF group, but there was no difference at two years (Fig. 4).

During the follow-up period, there was no difference in the need for household help between the two groups.

\section{Discussion}

The failure rate of $43 \%$ after IF in our study is equal to that reported by Bray et $\mathrm{al}^{9}$ and Lu-Yao et $\mathrm{al}^{7}{ }^{7}$ but somewhat

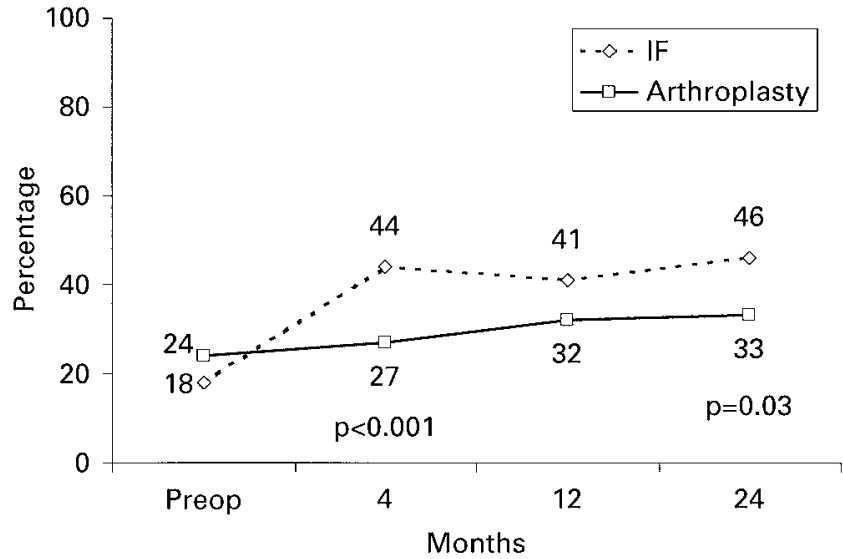

Fig. 2

Graph showing percentage of patients who were unable to walk up stairs.

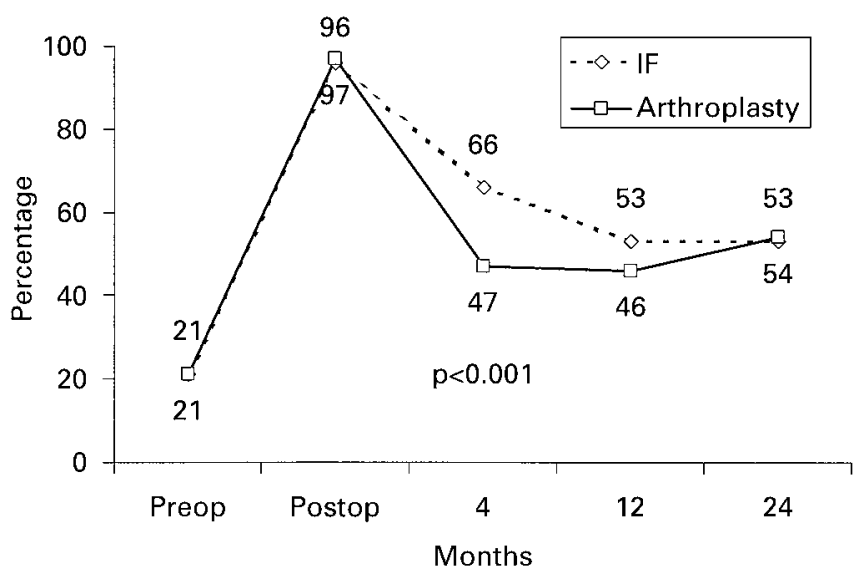

Fig. 4

Graph showing percentage of patients needing two crutches, a walker or other major walking aid.

higher than in other reports. ${ }^{10-13}$ Some of these last studies were by surgical teams with special skill and interest in the management of hip fractures. Our study reflects the reality for the average patient since all surgeons who treat hip fractures in our region contributed to the study. In our review, in which we excluded the weakest patients and those with dementia, almost all failures after IF resulted in an arthroplasty as a second procedure.

In the arthroplasty group we found a dislocation rate of $7.8 \%$, which is lower than that observed in other studies. ${ }^{6,14-16}$ Failure, defined as recurrent dislocations, loosening, deep infection or fracture adjacent to a prosthesis, occurred in $6 \%$ of the arthroplasty patients. This figure is equal to other contemporary studies concerning $\mathrm{THA}^{4,6,15}$ and hemiarthroplasty. ${ }^{17,18}$ Hudson et al ${ }^{19}$ had a higher rate of failure after hemiarthroplasty after eight years.

A two-year period of follow-up should reveal most of the potential failures in the IF group such as nonunion. ${ }^{20,21}$ 
Some of the complications in the arthroplasty group may occur later. ${ }^{22}$ There were nine patients who had IF and three with arthroplasties who had an uncertain outcome at two years.

When choosing between THA and hemiarthroplasty it has to be borne in mind that THA gives a better functional outcome in the active, independent senior citizen, but has a higher rate of dislocation. ${ }^{3,23,24}$ Hemiarthroplasty results in fewer dislocations, a shorter operating time and less need for blood transfusions, but there is a risk that acetabular erosion will limit the life of the implant. ${ }^{14,23}$ We have tried to assess the age and activity of the patient, and then to decide if THA or hemiarthroplasty was the proper choice. Given our relatively low rate of dislocation and good functional outcome we think that our score was of value in making the decision.

An argument against primary arthroplasty has been the possibility of increased postoperative mortality. Holmberg et $\mathrm{al}^{20}$ found a higher mortality three weeks after hemiarthroplasty than after IF, but their groups were not comparable since the mean age of the patients in the hemiarthroplasty group was six years older. The meta-analysis by Lu-Yao et $\mathrm{al}^{7}$ did not find a significant difference, but did note a slightly higher mortality 30 days after hemiarthroplasty compared with IF. By contrast, Hudson et al ${ }^{19}$ found a higher mortality after IF than after hemiarthroplasty when adjusted for age, gender and co-morbidities, but the selection criteria for the treatment in that study were not described. Often, the old and weak patient is given a hemiarthroplasty and the younger patient IF, and their mortality risks cannot be compared. We did not find any significant difference in mortality, neither did other randomised or comparative studies. ${ }^{2,12}$ The men in our study had a higher mortality than women, as has been previously reported by Eiskjaer and Ostgard ${ }^{25}$ and Holmberg et al. ${ }^{26}$

Overall, the arthroplasty group was better at walking and climbing stairs. They also had less pain when walking. Even at 24 months, when almost $40 \%$ of those with IF had had a conversion to arthroplasties because of failure, and when another $50 \%$ should have had healed fractures, the entire IF group showed a significantly worse functional result and more pain.

The need for walking aids was similar in the two groups before fracture, at discharge, and at 12 and 24 months after operation. Only at four months was the difference significant, the arthroplasty group having less need of walking aids, reflecting a faster rehabilitation. It can be assumed that this population has other reasons for using walking aids than the hip fracture. The need for daily help from others was presumably also because of co-morbidities and increasing age, and not just because of the hip fracture.

Our study consisted of selected patients, aged 70 years or more, who were mentally alert and independent. With no difference in mortality, with a high rate of failure in the IF group, and significantly better functional results in the arthroplasty group, we recommend primary arthroplasty when treating a displaced fracture of the femoral neck in this age range.

The Swedish NOA study group comprises Patrick Överli (Halmstad), Björn M. Persson, Niclas Ramberg, Ylva Hermodsson (Helsingborg), Mats Billsten (Hässleholm-Kristianstad), Christer Olsson (Karlshamn), Håkan Friberg (Karlskrona), Bertil Hofstadius (Landskrona), Mats Wilhelmsson (Ljungby), Karl-Göran Thorngren (Lund), Paul Gerdhem (Ystad), Lars Wahlström (Ängelholm), together with orthopaedic colleagues and physiotherapists in the above mentioned clinics. We thank $\mathrm{Mr}$ Jan-Åke Nilsson, Department of Internal Medicine, Malmö University Hospital, for his advice concerning statistics, and Mrs Tanja Andersson for secretarial assistance. Financial support was obtained from Trygg-Hansa Research Foundation, Greta \& Johan Kock Foundation and the Malmö University Hospital Research Funds.

No benefits in any form have been received or will be received from a commercial party related directly or indirectly to the subject of this article.

\section{References}

1. Sernbo I, Fredin H. Changing methods of hip fracture osteosynthesis in Sweden: an epidemiological enquiry covering 46900 cases. Acta Orthop Scand 1993;64:173-4.

2. Sikorski JM, Barrington R. Internal fixation versus hemiarthroplasty for the displaced subcapital fracture of the femur: a prospective randomised study. J Bone Joint Surg [Br] 1981;63-B:357-61.

3. Søreide O, Mölster A, Raugstad TS. Internal fixation versus primary prosthetic replacement in acute femoral neck fractures: a prospective, randomized clinical study. Br J Surg 1979;66:56-60.

4. Jonsson B, Sernbo I, Carlsson A, Fredin H, Johnell O. Social function after cervical hip fracture: a comparison of hook-pins and total hip replacement in 47 patients. Acta Orthop Scand 1996;67:431-4.

5. Parker MJ, Pryor GA. Internal fixation or arthroplasty for displaced cervical hip fractures in the elderly: a randomised controlled trial of 208 patients. Acta Orthop Scand 2000;71:440-6.

6. Skinner P, Riley D, Ellery J, et al. Displaced subcapital fractures of the femur: a prospective randomised comparison of internal fixation, hemiarthroplasty and total hip replacement. Injury 1989;20:291-3.

7. Lu-Yao GL, Keller RB, Littenberg B, Wennberg JE. Outcomes after displaced fractures of the femoral neck: a meta-analysis of one hundred and six published reports. J Bone Joint Surg [Am] 1994;76-A:15-25.

8. Garden RS. Low-angle fixation in fractures of the femoral neck. J Bone Joint Surg [Br] 1961;43-B:647-63.

9. Bray TJ, Smith-Hoefer E, Hooper A, Timmerman L. The displaced femoral neck fracture: internal fixation versus bipolar endoprosthesis. Clin Orthop 1988;230:127-40.

10. Strömqvist B, Hansson LI, Nilsson LT, Thorngren K-G. Hook-pin fixation in femoral neck fractures: a two-year follow-up study of 300 cases. Clin Orthop 1987;218:58-62.

11. Stromqvist B, Nilsson LT, Thorngren KG. Femoral neck fracture fixation with hook-pins: 2-year results and learning curve in 626 prospective cases (see comments). Acta Orthop Scand 1992;63:282-7.

12. Parker MJ. Internal fixation or arthroplasty for displaced subcapital fractures in the elderly? Injury 1992;23:521-4.

13. Rehnberg L, Olerud C. Subchondral screw fixation for femoral neck fractures. J Bone Joint Surg [Br] 1989;71-B:178-80.

14. Dorr LD, Glousman R, Sew Hoy AL, Vanis R, Chandler $R$. Treatment of femoral neck fractures with total hip replacement versus cemented and noncemented hemiarthroplasty. J Arthroplasty 1986;1:21-8.

15. Gregory RJ, Wood DJ, Stevens J. Treatment of displaced subcapital femoral fractures with total hip replacement. Injury 1992;23:168-70.

16. Taine WH, Armour PC. Primary total hip replacement for displaced subcapital fractures of the femur. $J$ Bone Joint Surg $[\mathrm{Br}]$ 1985;67-B:214-7.

17. Lennox IA, McLauchlan J. Comparing the mortality and morbidity of cemented and uncemented hemiarthroplasties. Injury 1993;24:185-6. 
18. Calder SJ, Anderson GH, Jagger C, Harper WM, Gregg PJ. Unipolar or bipolar prosthesis for displaced intracapsular hip fracture in octogenarians: a randomised prospective study. J Bone Joint Surg [Br] 1996;78-B:391-4.

19. Hudson JI, Kenzora JE, Hebel JR, et al. Eight-year outcome associated with clinical options in the management of femoral neck fractures. Clin Orthop 1998;348:59-66.

20. Holmberg S, Kalén R, Thorngren K-G. Treatment and outcome of femoral neck fractures: an analysis of 2418 patients admitted from their own homes. Clin Orthop 1987:218:42-52.

21. Nilsson LT, Strömqvist B, Thorngren K-G. Secondary arthroplasty for femoral neck fracture complication. J Bone Joint Surg [Br] 1989;71-B:777-81.
22. Eiskjaer S, Ostgard SE. Survivorship analysis of hemiarthroplasties. Clin Orthop 1993;286:206-11.

23. Gebhard JS, Amstutz HC, Zinar DM, Dorey FJ. A comparison of total hip arthroplasty and hemiarthroplasty for treatment of acute fracture of the femoral neck. Clin Orthop 1992;282:123-31.

24. Squires B, Bannister G. Displaced intracapsular neck of femur fractures in mobile independent patients: total hip replacement or hemiarthroplasty? Injury 1999;30:345-8.

25. Eiskjaer S, Ostgard SE. Risk factors influencing mortality after bipolar hemiarthroplasty in the treatment of fracture of the femoral neck. Clin Orthop 1991;270:295-300.

26. Holmberg S, Conradi P, Kalen R, Thorngren KG. Mortality after cervical hip fracture: 3002 patients followed for 6 years. Acta Orthop Scand 1986;57:8-11. 